\title{
Effect of Cooling Rate on Superelasticity and Microstructure Evolution in Ti-10V-2Fe-3Al and Ti-10V-2Fe-3Al-0.2N Alloys
}

\author{
Yusaku Tomio ${ }^{1, * 1}$, Tadashi Furuhara ${ }^{2}$ and Tadashi Maki ${ }^{3, * 2}$ \\ ${ }^{1}$ Department of Metallurgy, Tohoku University, Sendai 980-8577, Japan \\ ${ }^{2}$ Institute for Materials Research, Tohoku University, Sendai 980-8577, Japan \\ ${ }^{3}$ Nippon Steel Co., Futtu 293-8511, Japan
}

A Ti-10V-2Fe-3Al alloy with a small amount of nitrogen shows superelasticity. Controlling of the cooling rate from $\beta$ solution treatment temperature improves superelasticity in both Ti-10V-2Fe-3Al and Ti-10V-2Fe3-Al-0.2N alloys. In this study, a wider range of the cooling rate was examined and microstructure change during slow cooling was investigated through examining quenched and aged specimens by means of hardness and resistivity measurement and transmission electron microscopy. Although superelasticity is improved with a decrease in the cooling rate up to $22 \mathrm{~K} / \mathrm{s}$ for the $\mathrm{N}$-free alloy and up to $50 \mathrm{~K} / \mathrm{s}$ for the $0.2 \mathrm{~N}$ alloy, there is no obvious change in microstructure. It is clarified from the observation of specimens quenched and aged at the temperature range where superelasticity is improved that the $\beta$ phase decomposition occurs through isothermal $\omega$ phase precipitation. Therefore, microstructure evolution during slow cooling is considered to be precipitation of isothermal $\omega$ phase or its precursor phenomena. [doi:10.2320/matertrans.MA200909]

(Received June 1, 2009; Accepted July 27, 2009; Published September 30, 2009)

Keywords: titanium alloy, superelasticity, cooling rate, nitrogen, phase decomposition

\section{Introduction}

The shape memory effect in $\beta$ titanium alloys due to stress induced $\beta$ (bcc) $\rightarrow \alpha^{\prime \prime}$ (orthorhombic) martensitic transformation was first found by Baker in a Ti-Nb binary alloy. ${ }^{1)}$ Since then, several $\beta$ titanium alloys exhibiting the shape memory effect and/or superelasticity have been reported in $\mathrm{Ti}-\mathrm{Mo}-\mathrm{Al}^{2)}$ and $\mathrm{Ti}-\mathrm{V}-\mathrm{Al}^{3)}$ ternary alloys and in a Ti-10V$2 \mathrm{Fe}-3 \mathrm{Al}$ alloy ${ }^{4)}$ which is one of the practical titanium alloys for structural use. Recently, much attention has been paid to $\mathrm{Ni}$-free $\beta$ titanium shape memory and superelastic alloys for biomedical use due to the cytotoxicity of $\mathrm{Ni}$, leading to the recent development of Ti-Nb based ${ }^{5-9)}$ and Ti-Mo based ${ }^{10-12)}$ alloys. Previous studies mostly focused on finding out the optimum composition for shape recovery in the $\beta$ quenched state. In conventional shape memory alloys such as $\mathrm{Ti}-\mathrm{Ni}$ alloys, its shape memory and superelastic properties are often improved by heat treatments after the solution treatment. In development of $\beta$ titanium shape memory alloys, however, there are only several studies on the enhancement of the shape memory effect or superelasticity by controlling the cooling rate from $\beta$-solution temperature ${ }^{5)}$ or aging after solution treatment. ${ }^{6,13-15)}$ Optimum microstructure and processing conditions for the enhancement of the shape memory effect or superelasticity in $\beta$ titanium alloys have not been well understood yet. Recently, an appearance of superelasticity was reported in a $\mathrm{Ti}-10 \mathrm{~V}-2 \mathrm{Fe}-3 \mathrm{Al}$ alloy with a small amount of nitrogen after solution treatment. ${ }^{16,17)}$ It was found that nitrogen addition suppresses the thermally induced martensitic transformation during quenching and promotes the superelasticity at room temperature by solid solution hardening and suppression of athermal- $\omega$ transformation. ${ }^{17)}$ It was also reported that controlling of the cooling rate from the

\footnotetext{
${ }^{* 1}$ Graduate Student, Tohoku University. Present address: Corporate Research and Development Laboratories, Sumitomo Metal Industries, Ltd., Amagasaki 660-0891, Japan

${ }^{*}$ Professor Emeritus, Kyoto University
}

$\beta$ solutionizing temperature improves superelasticity both in Ti-10V-2Fe-3Al and Ti-10V-2Fe3-Al-0.2N alloys. ${ }^{18)}$ In the present study, the effect of the cooling rate was further examined in a wider range, and the microstructure favorable for superelasticity was investigated by using specimens continuously cooled or quenched and aged at various temperatures.

\section{Experimental Procedure}

Ti-10V-2Fe-3Al and Ti-10V-2Fe-3Al-0.2N (mass\%) alloys (hereafter $\mathrm{N}$-free and $0.2 \mathrm{~N}$ alloys, respectively) were used in this study. Table 1 shows chemical compositions of these alloys. Specimens of the $\mathrm{N}$-free alloy were cut to $3 \mathrm{~mm}$, $6 \mathrm{~mm}$ or $15 \mathrm{~mm}$ in thickness by electro-discharge machining from a hot-rolled plate. The $0.2 \mathrm{~N}$ alloy was prepared by arcmelting in an Ar atmosphere from the $\mathrm{N}$-free alloy and TiN powder. The arc-melted bars were encapsulated in a quartz tube with an Ar atmosphere and were homogenized at $1373 \mathrm{~K}$ for $86.4 \mathrm{ks}$ followed by furnace cooling. The homogenized bars were hot rolled at $973 \mathrm{~K}$ to $3 \mathrm{~mm}$ or $6 \mathrm{~mm}$ thickness. After the plates were wrapped by Ti foil, solution treatment was conducted in a vacuum furnace at $1123 \mathrm{~K}$ for $3.6 \mathrm{ks}$ for the $\mathrm{N}$-free alloy and at $1273 \mathrm{~K}$ for $1.8 \mathrm{ks}$ for the $0.2 \mathrm{~N}$ alloy, respectively, followed by iced brine quenching (I.B.Q.), oil quenching (O.Q.) or air cooling (A.C.). Average cooling rates between $1073 \mathrm{~K}$ and $373 \mathrm{~K}$ of each thickness and method are shown in Table 2. Part of specimens quenched into iced brine was subjected to aging treatment at $473 \mathrm{~K}, 673 \mathrm{~K}$ and $873 \mathrm{~K}$. Microstructure was observed by optical microscopy and transmission electron microscopy (TEM). The thin films for TEM observations were prepared by an electro-polishing method at $213 \mathrm{~K}$ using methanol $-5 \%$ sulfuric acid solution. A cyclic tensile test was carried out at an initial strain rate of $2.0 \times 10^{-4} \mathrm{~s}^{-1}$ using specimens with a gauge section of $8.5 \mathrm{~mm}^{1} \times 3 \mathrm{~mm}^{\mathrm{w}} \times 0.5 \mathrm{~mm}^{\mathrm{t}}$. In each cycle, the applied strain was increased by $0.5 \%$. Recovered strain against applied strain was evaluated from the stress-strain curve measured by a strain-gauge method. The strain recovered 
Table 1 Chemical composition of the alloys used. (mass\%)

\begin{tabular}{ccccccc}
\hline & $\mathrm{V}$ & $\mathrm{Fe}$ & $\mathrm{Al}$ & $\mathrm{N}$ & $\mathrm{O}$ & $\mathrm{Ti}$ \\
\hline $\mathrm{N}$-free & 9.67 & 1.81 & 3.04 & 0.009 & 0.063 & Bal. \\
\hline $0.2 \mathrm{~N}$ & 10.04 & 1.98 & 3.17 & 0.20 & 0.096 & Bal.
\end{tabular}

Table 2 Cooling rates for various specimen thicknesses and cooling methods.

\begin{tabular}{ccccc}
\hline thickness & $3 \mathrm{~mm}$ & $6 \mathrm{~mm}$ & $10 \mathrm{~mm}$ & $15 \mathrm{~mm}$ \\
\hline I.B.Q. & $270 \mathrm{~K} / \mathrm{s}$ & $160 \mathrm{~K} / \mathrm{s}$ & $77 \mathrm{~K} / \mathrm{s}$ & - \\
\hline O.Q. & - & $50 \mathrm{~K} / \mathrm{s}$ & - & $22 \mathrm{~K} / \mathrm{s}$ \\
\hline A.C. & $2 \mathrm{~K} / \mathrm{s}$ & - & - & - \\
\hline
\end{tabular}
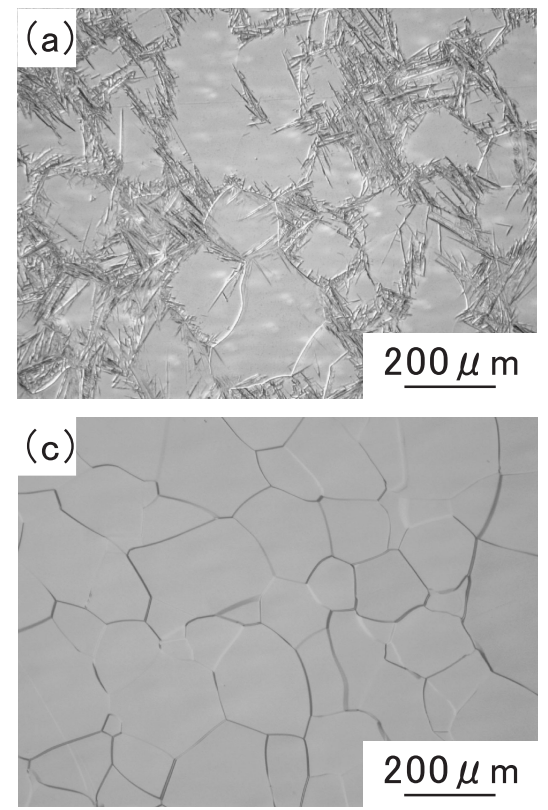

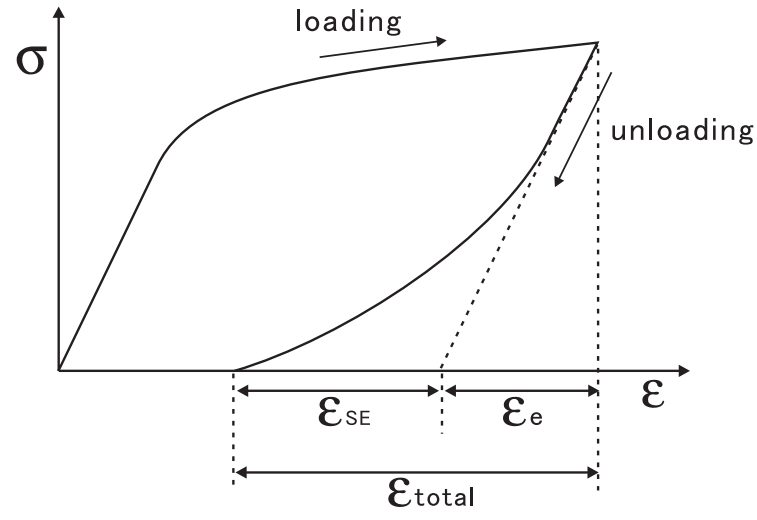

Fig. 1 Schematic illustration of applied and recovered strains in a cyclic tensile test.
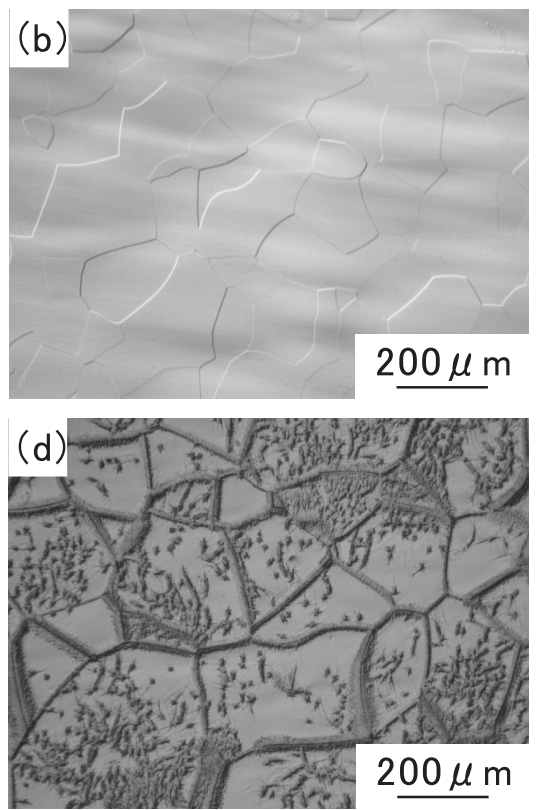

Fig. 2 Optical micrographs of $\mathrm{N}$-free alloys cooled at (a) $270 \mathrm{~K} / \mathrm{s}$ and (b) $50 \mathrm{~K} / \mathrm{s}$ and $0.2 \mathrm{~N}$ alloys cooled at (c) $270 \mathrm{~K} / \mathrm{s}$ and (d) $2 \mathrm{~K} / \mathrm{s}$.

during unloading $\left(\varepsilon_{\text {total }}\right)$ consists of two components, which is schematically described in Fig. 1. One is the ordinary elastic strain $\left(\varepsilon_{\mathrm{e}}\right)$ and the other is strain recovered by superelasticity $\left(\varepsilon_{\mathrm{SE}}\right)$, which is the result of reverse transformation from $\alpha^{\prime \prime}$ martensite to $\beta$ matrix. These strains are separated by taking an average slope of the stress-strain curve up to $0.3 \%$ strain at the beginning of loading as a representative Young's modulus. Bending test of a sheet specimen with $0.25 \mathrm{~mm}$ in thickness was performed at room temperature. The bend angle and radius of curvature are 110 degrees and $5 \mathrm{~mm}$, respectively. Recovered ratio after unloading was determined to be the ratio of the recovered bend angle to 110 degrees. Electrical resistivity was measured by direct current fourterminal electric resistance method using specimens with a gauge section of $10 \mathrm{~mm}^{1} \times 3 \mathrm{~mm}^{\mathrm{w}} \times 0.25 \mathrm{~mm}^{\mathrm{t}}$.

\section{Results}

\subsection{Initial microstructure}

Figures 2(a) and (b) show optical micrographs of the Nfree alloy cooled at $270 \mathrm{~K} / \mathrm{s}$ and $50 \mathrm{~K} / \mathrm{s}$, respectively. Large volume fraction of $\alpha^{\prime \prime}$ martensite is observed in the specimen cooled at $270 \mathrm{~K} / \mathrm{s}$. With a decrease in the cooling rate, the volume fraction of $\alpha^{\prime \prime}$ martensite decreases, and $\alpha^{\prime \prime}$ martensite does not form in specimens cooled at the rates slower than $50 \mathrm{~K} / \mathrm{s}$. Even at $2 \mathrm{~K} / \mathrm{s}$, which is the slowest cooling rate in this study, no precipitation of equilibrium $\alpha$ phase is observed. Figures 2(c) and (d) show optical micrographs of $0.2 \mathrm{~N}$ alloys cooled at $270 \mathrm{~K} / \mathrm{s}$ and $2 \mathrm{~K} / \mathrm{s}$, respectively. As previously reported, ${ }^{12}$ thermally induced martensite is completely suppressed by 0.2 mass $\%$ nitrogen addition even at the highest cooling rate of $270 \mathrm{~K} / \mathrm{s}$. Precipitation of equilibrium $\alpha$ phase from $\beta$ grain boundary is observed only at the slowest rate of $2 \mathrm{~K} / \mathrm{s}$. Hardness increases largely by an addition of $0.2 \%$ nitrogen and increases slightly with a decrease in the cooling rate in both alloys as shown in Fig. 3. No obvious change in microstructure of $\beta$ matrix is observed between $\mathrm{N}$-free alloys cooled at $22 \mathrm{~K} / \mathrm{s}$ and $270 \mathrm{~K} / \mathrm{s}$ even by transmission electron microscopy as shown in Fig. 4.

Figure 5 shows stress-strain curves obtained from the cyclic tensile tests of $\mathrm{N}$-free alloys at room temperature. Yield stress corresponding to the stress for inducing 


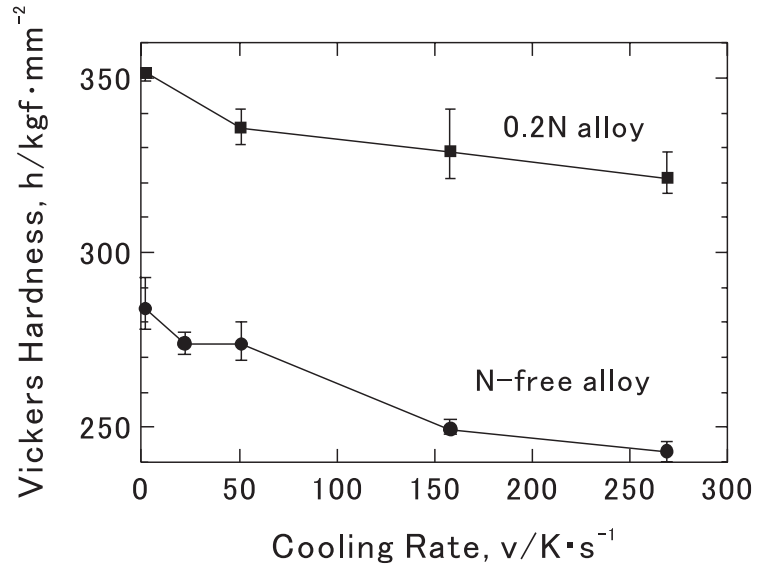

Fig. 3 Change in Vickers hardness of the $\beta$ matrix with cooling rate in $\mathrm{N}$ free and $0.2 \mathrm{~N}$ alloys.
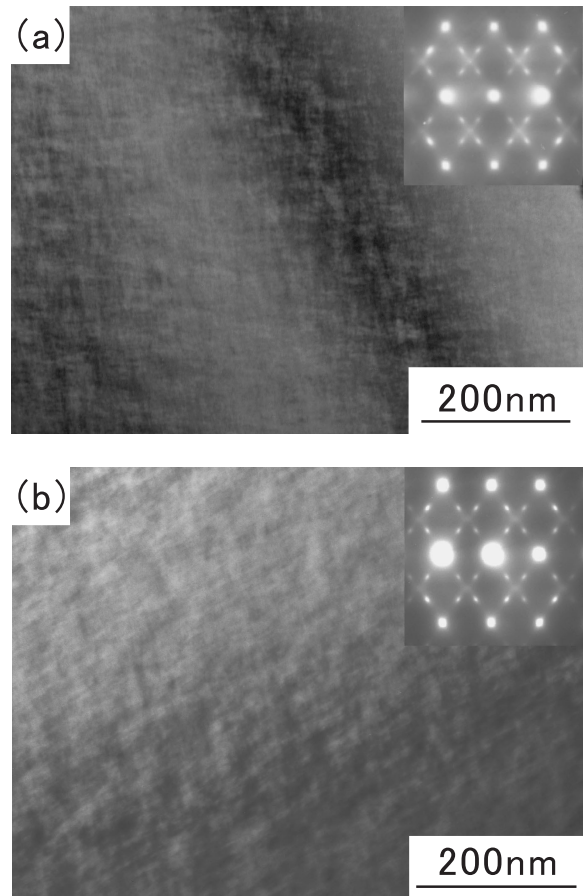

Fig. 4 TEM micrographs of $\beta$ matrix of $\mathrm{N}$-free alloy cooled at (a) $270 \mathrm{~K} / \mathrm{s}$ and (b) $22 \mathrm{~K} / \mathrm{s}$.

martensite transformation increases with a decrease in the cooling rate. At the rate of $270 \mathrm{~K} / \mathrm{s}$ and $160 \mathrm{~K} / \mathrm{s}$, strain recovers almost linearly during unloading with almost the same slope as loading in an elastic region. On the other hand, non-linear recovery is observed at the rate of $50 \mathrm{~K} / \mathrm{s}$ and $22 \mathrm{~K} / \mathrm{s}$. In those conditions, two-step yielding indicated by arrows is observed in the second and latter cycles. In the specimen cooled at $2 \mathrm{~K} / \mathrm{s}$, yield stress exceeds $600 \mathrm{MPa}$ and recovery during unloading is almost linear. In order to examine stress induced martensitic transformation behaviors during the cyclic tensile tests, in-situ observation of surface relief by optical microscope during tensile deformation was conducted. Figure 6 shows a change in microstructure during tensile deformation of the $\mathrm{N}$-free alloy cooled at $22 \mathrm{~K} / \mathrm{s}$. The surface relief of the stress-induced martensite appears on the polished surface by deformation (Fig. 6(b)). The number and the thickness of relieves increase with increasing of the (a)

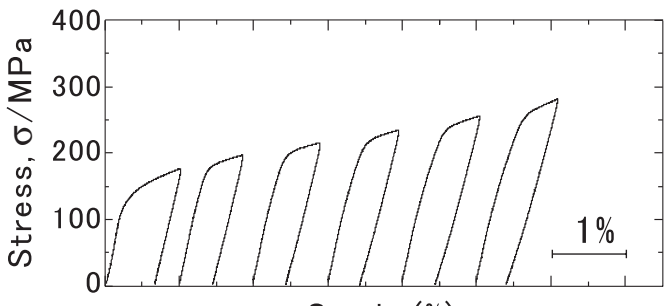

(b)

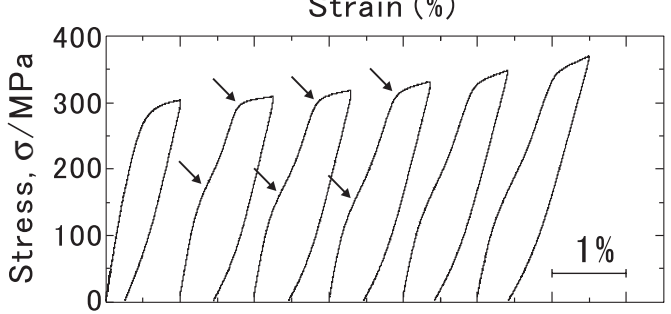

Strain (\%)

(c)

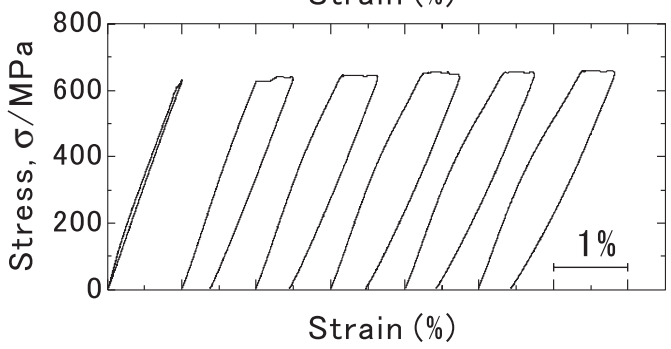

Fig. 5 Stress-strain curves in the cyclic tensile test of $\mathrm{N}$-free alloys cooled at (a) $270 \mathrm{~K} / \mathrm{s}$, (b) $22 \mathrm{~K} / \mathrm{s}$ and (c) $2 \mathrm{~K} / \mathrm{s}$.

applied strain (Fig. 6(c)). It partially disappears during unloading (Fig. 6(d)). In the second cycle, the same relief which is formed by deformation and disappears during unloading in the first cycle is observed. The number of relieves is larger than that in the first cycle even at the same applied strain of $0.5 \%$ as shown in Fig. 6(e). It is clear from this observation that superelasticity by stress-induced martensite transformation and its reversion certainly occurs in this specimen and the first yielding in two-step yielding corresponds to the stress for inducing the same martensite plate formed in the previous cycle and the second yielding does to the stress for formation of new martensite plate. Figure 7 shows variation of the recovered strain of $\mathrm{N}$-free alloys against the applied strain in the cyclic tensile test. The recovered strain of the specimen cooled at $270 \mathrm{~K} / \mathrm{s}$ is $0.8 \%$ against the total applied strain of $4.0 \%$. The recovered strain increases with decreasing the cooling rate because of the increase in yield stress and superelasticity in the specimen cooled at $50 \mathrm{~K} / \mathrm{s}$ or $22 \mathrm{~K} / \mathrm{s}$. However, the proportion of elastic recovery is much larger than that of superelasticity.

Figure 8 shows stress-strain curves of cyclic tensile tests of the $0.2 \mathrm{~N}$ alloys cooled at the rate of (a) $270 \mathrm{~K} / \mathrm{s}$ and (b) $50 \mathrm{~K} / \mathrm{s}$, respectively. Even the specimen cooled at $270 \mathrm{~K} / \mathrm{s}$ exhibits superelasticity. By decreasing the cooling rate, yield stress increases and superelastic behavior becomes prominent. Furthermore, all of the $0.2 \mathrm{~N}$ alloys except for the specimen cooled at $2 \mathrm{~K} / \mathrm{s}$ show multi-step yielding, which is indicated by arrows. This phenomenon is attributed to a decrease in stress for inducing the martensite plate formed previously with increasing the number of cycles. In the specimen cooled at the rate of $2 \mathrm{~K} / \mathrm{s}$, however, premature failure occurs in elastic region where applied strain is less 

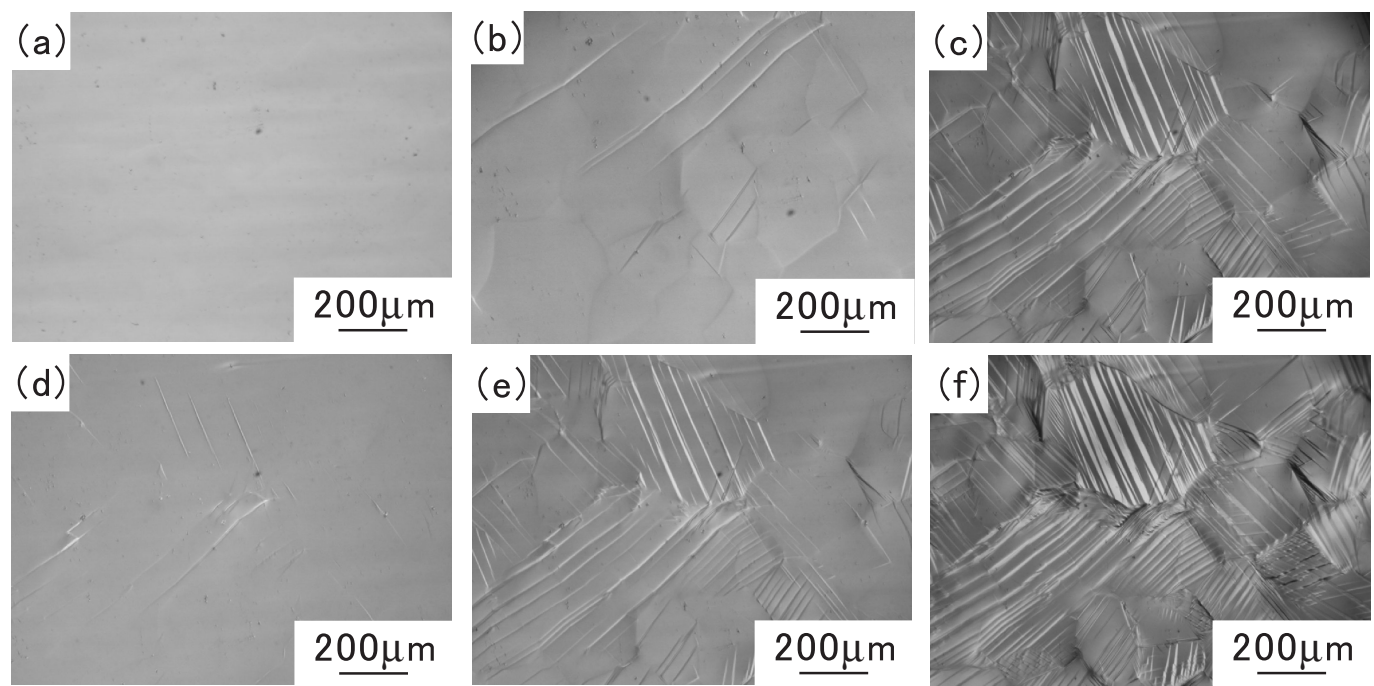

Fig. 6 Change in microstructure during tensile deformation in the $\mathrm{N}$-free alloy cooled at $22 \mathrm{~K} / \mathrm{s}$ : (a) before loading, (b) after $0.5 \%$ deformation, (c) after 1.0\% deformation (d) after unloading and (e) after $0.5 \%$ re-deformation (f) after $1.5 \%$ deformation.

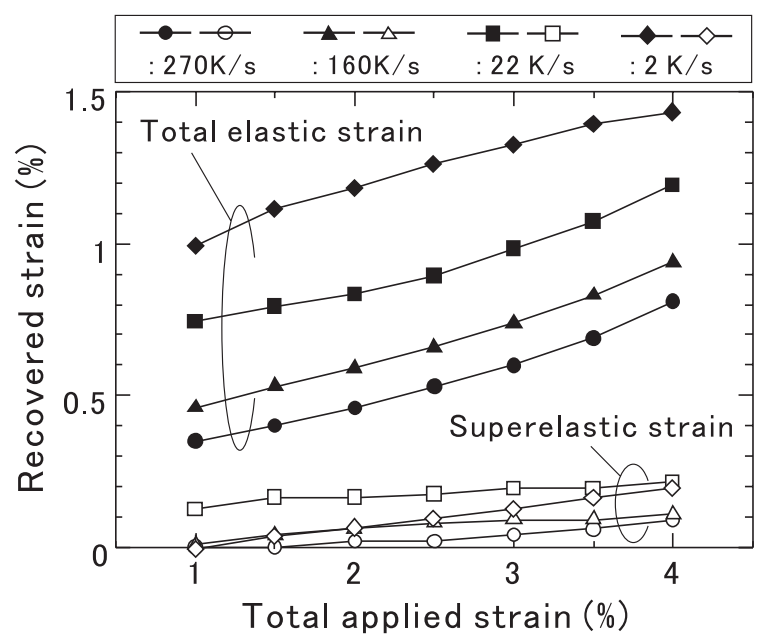

Fig. 7 Variation of the recovered strain of N-free alloys against applied strain.

than $1.5 \%$. Figure 9 shows change in the recovered strain of the $0.2 \mathrm{~N}$ alloys against applied strain. The recovered strain of the $0.2 \mathrm{~N}$ alloys cooled at $270 \mathrm{~K} / \mathrm{s}$ and $160 \mathrm{~K} / \mathrm{s}$ reaches the maximum strain when the applied strain is $2.0 \%$, and it remains nearly the same value with a further increase in the applied strain. The maximum recovered strain is $3.2 \%$ in total elastic strain and $1.8 \%$ in superelastic strain in the $0.2 \mathrm{~N}$ alloy cooled at $50 \mathrm{~K} / \mathrm{s}$.

\section{Discussion}

In this section, the reason why superelasticity is promoted by decreasing the cooling rate is discussed. Compared to rapidly quenched specimens, slowly cooled specimens undergo an aging at various temperatures during cooling. In such a case, metastable $\beta$ phase decomposes into more stable phases. Three ways of $\beta$ phase decomposition by a diffusional process have been reported in metastable $\beta$ titanium alloys. One is precipitation of equilibrium $\alpha$ phase and the others are precipitation of isothermal $\omega$ phase $^{19)}$ and $\beta$ phase separation. ${ }^{20)}$ If such diffusional decomposition occurs, (a)

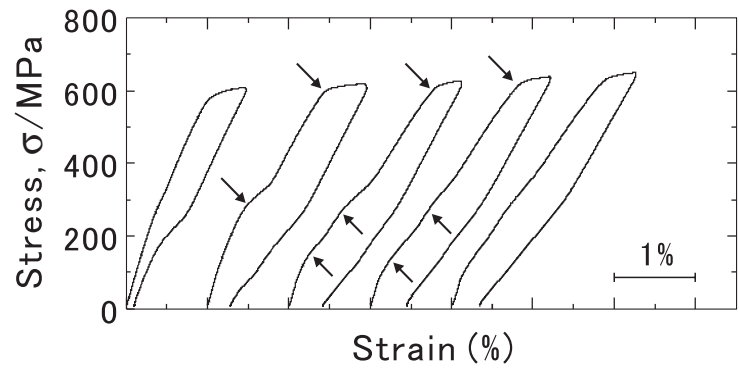

(b)

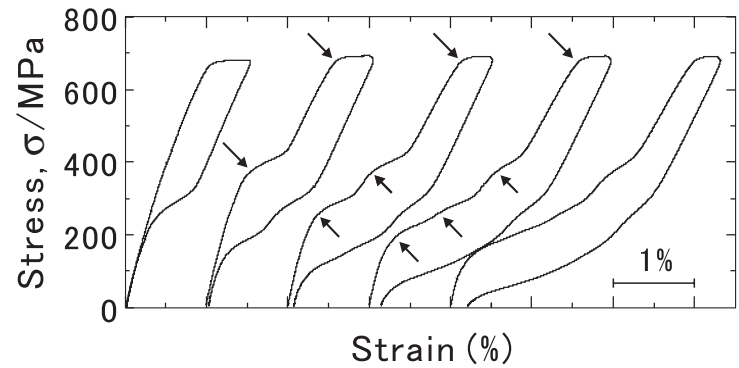

Fig. 8 Stress-strain curves in the cyclic tensile tests of $0.2 \mathrm{~N}$ alloys cooled at (a) $270 \mathrm{~K} / \mathrm{s}$ and (b) $50 \mathrm{~K} / \mathrm{s}$.

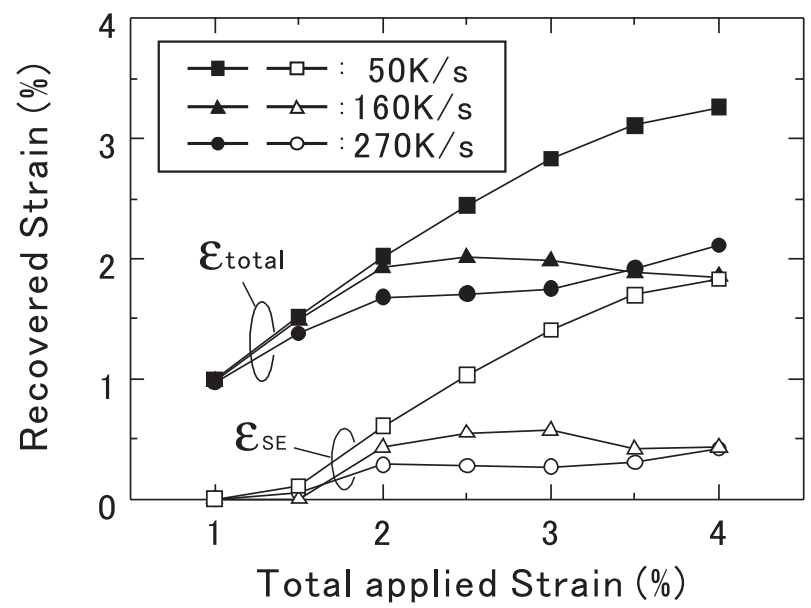

Fig. 9 Variation of the recovered strain of $0.2 \mathrm{~N}$ alloys against applied strain. 
(a)

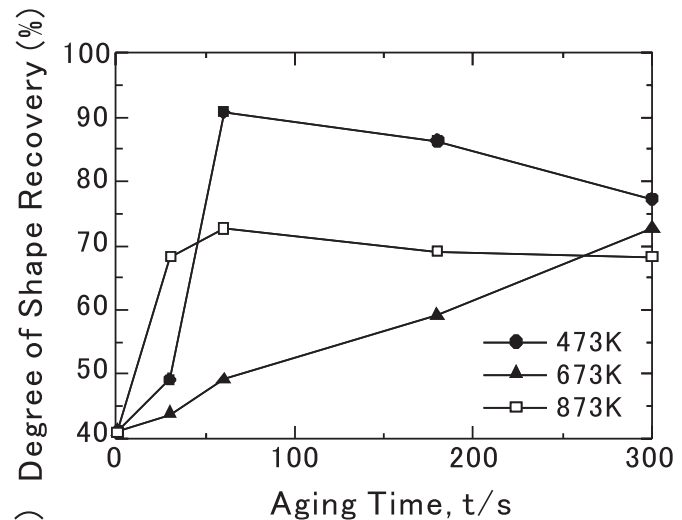

(b)

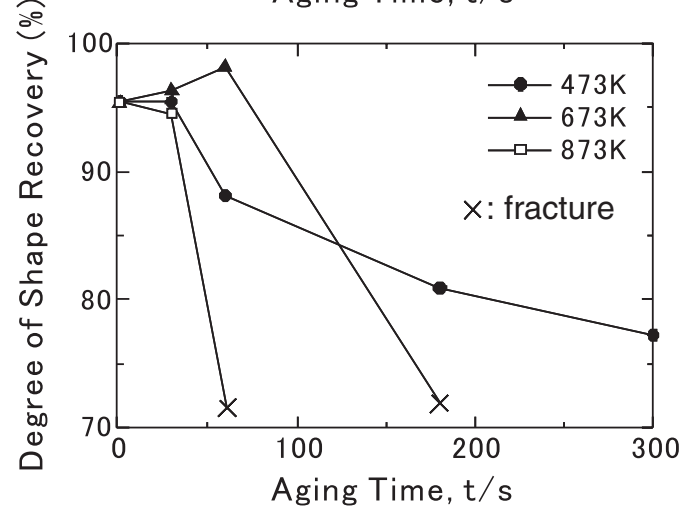

Fig. 10 Change in degree of shape recovery with aging time at various temperature in (a) $\mathrm{N}$-free and (b) $0.2 \mathrm{~N}$ alloys.

the concentration of the $\beta$-stabilizer in the matrix is increased and the strength of $\beta$ matrix is changed by precipitation hardening and solution hardening. These microstructural changes should have strong effects on superelastic behavior. Therefore, microstructure evolution during slow cooling was investigated through examining the specimens rapidly quenched and aged at 473, 673 and $873 \mathrm{~K}$.

First of all, the bending test was carried out. Figure 10 shows degrees of shape recovery against aging time. In the $\mathrm{N}$ free alloy (Fig. 10(a)), degree of shape recovery is remarkably increased by aging at $473 \mathrm{~K}$ for $60 \mathrm{~s}$ but is degraded gradually by the further aging. At $673 \mathrm{~K}$ degree of shape recovery is gradually increased by aging. At $873 \mathrm{~K}$ degree of shape recovery is increased quickly by aging of $60 \mathrm{~s}$ and it is hardly changed by the further aging. On the other hand, in the case of $0.2 \mathrm{~N}$ alloy (Fig. 10(b)), degree of shape recovery increases only by aging at $673 \mathrm{~K}$ for periods up to $60 \mathrm{~s}$. The optical microscopy confirms that the microstrucual change at $873 \mathrm{~K}$ is $\alpha$ phase precipitation, but no obvious microsructure change is observed in the specimens aged at $473 \mathrm{~K}$ and $673 \mathrm{~K}$. To clarify the decomposition behavior, change in electrical resistivity during isothermal aging at $473 \mathrm{~K}$ and $673 \mathrm{~K}$ was examined. Figure 11 shows change in resistivity of $\mathrm{N}$-free and $0.2 \mathrm{~N}$ alloys aged at $473 \mathrm{~K}$ and $673 \mathrm{~K}$. Resistivity is increased by aging at $473 \mathrm{~K}$ and decreased by aging at $673 \mathrm{~K}$ in both alloys. Since the shape of the curve of the $0.2 \mathrm{~N}$ alloy is quite similar to that of the $\mathrm{N}$-free alloy, there seems to be little difference in aging behavior. Large difference in degree of shape recovery in Fig. 10 is not due to the effect of nitrogen on aging behavior but due to effect of nitrogen addition on the martensitic transformation and strength of (a)

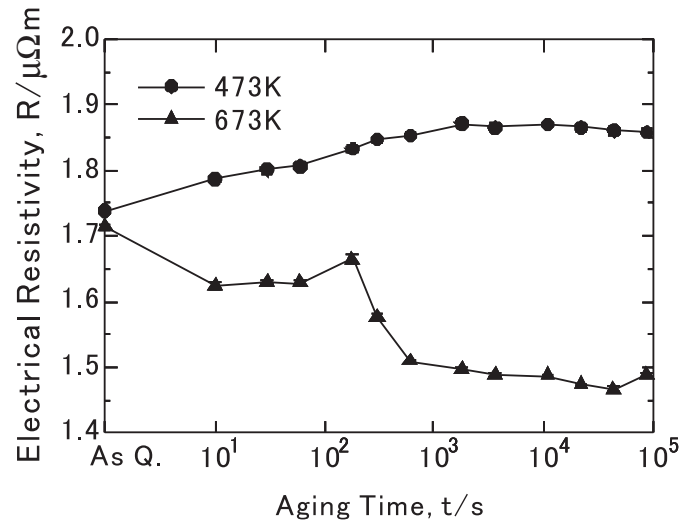

(b)

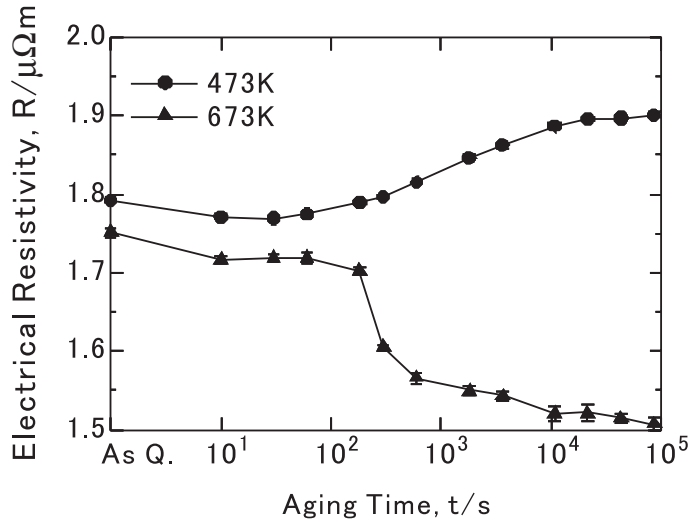

Fig. 11 Change in electrical resistivity with aging time at $473 \mathrm{~K}$ and $673 \mathrm{~K}$ in (a) $\mathrm{N}$-free and (b) $0.2 \mathrm{~N}$ alloys.

matrix. The decrease in resistivity is explained as formation of isothermal $\omega$ phase as reported previously by Komatsu et al. ${ }^{21)}$ In fact, Ohrmori et al. reported that metastable $\beta$ phase decomposes at $673 \mathrm{~K}$ through precipitation of isothermal $\omega$ phase in a Ti-10V-2Fe-3Al alloy. ${ }^{22)}$ On the other hand, the increase in resistivity is attributed to the fluctuation of the concentration of alloying elements such as G.P. zone or spinodal decomposition ${ }^{23)}$ although there is no clear evidence in $\beta$ titanium alloys at the present time. To clarify the origin of the increase in electrical resistivity, the microstructure change, especially the change in $\omega$ diffraction spots, during aging at $473 \mathrm{~K}$ was examined by TEM. In this experiment, the $0.2 \mathrm{~N}$ alloy was used because its $\omega$ diffraction spots in the as-quenched state are relatively diffuse. Figure 12 shows TEM observation results of the $0.2 \mathrm{~N}$ alloy quenched and aged at $473 \mathrm{~K}$ for $86.4 \mathrm{ks}$ where electrical resistivity reaches the maximum value. Compared to the as-quenched state (Fig. 12(a)), diffraction spots from $\omega$ phase are more obvious (Fig. 12(b)). This experimental result shows that the increase in electrical resistivity is also attributed to the precipitation of isothermal $\omega$ phase or its precursor. Based on the discussion above, we conclude that isothermal $\omega$ phase precipitation or its precursor phenomenon occurs during aging at $473 \mathrm{~K}$ and $673 \mathrm{~K}$ whereas equilibrium $\alpha$ phase precipitates at $873 \mathrm{~K}$.

The difference in the change of degree of shape recovery in the $\mathrm{N}$-free alloy is explained as follows. At $473 \mathrm{~K}$ progress of isothermal $\omega$ phase precipitation is relatively slow. The relation between martensite transformation temperature, reverse transformation temperature and room temperature is optimized by $60 \mathrm{~s}$ aging and degree of shape recovery is increased drastically. Further aging decreases martensite 

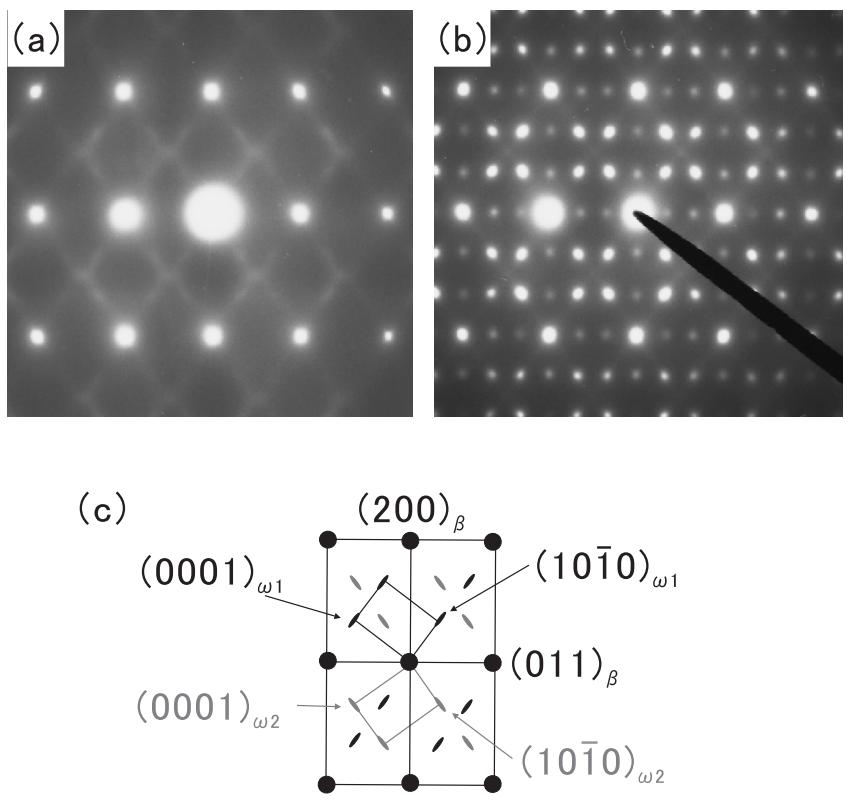

incident beam // $[01 \overline{1}]_{\beta}$

Fig. 12 Selected area diffraction patterns obtained from $\beta$ matrixes in $0.2 \mathrm{~N}$ alloys: (a) as quenched (cooled at $270 \mathrm{~K} / \mathrm{s}$ ) (b) quenched and aged at $473 \mathrm{~K}$ for $86.4 \mathrm{ks}$ (c) their key diagram.

transformation temperature, which leads an increase in stress for inducing martensitic transformation. Superelastic recovery decreases with occurrence of plastic deformation in matrix because of an increase in stress for inducing martensitic transformation. Therefore, degree of shape recovery becomes small with aging time. At $673 \mathrm{~K}$, since progress of isothermal $\omega$ phase precipitation is relatively fast, martensitic transformation temperature decreases largely and stress for inducing martensitic transformation exceeds the stress required for plastic deformation. The specimen is deformed only by plastic deformation. An increase in yield stress due to progress of $\omega$ precipitation and subsequent $\alpha$ precipitation results in an increase in degree of shape recovery. At $873 \mathrm{~K}$, $\alpha$ phase precipitation occurs in the beginning of the aging treatment which results in a large increase in yield stress and degree of shape recovery. Microstructure and yield stress hardly changes by the further aging, which results in almost constant degree of shape recovery after $30 \mathrm{~s}$ aging.

In the specimen continuously cooled within $60 \mathrm{~s}, \alpha$ phase precipitation is not observed and shape recovery is improved. Thus, based upon isothermal aging experiments, it is considered that the microstructure change during slow cooling is isothermal $\omega$ phase precipitation or its precursor phenomenon. Nitrogen addition improves superelasticity by increasing the strength of $\beta$ matrix by solid solution hardening and decreasing martensitic transformation and reverse transformation temperatures. On the other hand, precipitation of isothermal $\omega$ phase or its precursor phenomenon increases both the concentration of $\beta$-stabilizing elements and the strength of $\beta$ matrix. And also an increase in concentration of $\beta$ stabilizing elements decreases martensite transformation temperature and reverse martensite transformation temperature. It is considered that appropriate level of this reaction leads to optimization of superelasticity.

\section{Conclusion}

Variations of superelasticity of Ti-10V-2Fe-3Al (N-free) and Ti-10V-2Fe-3Al-0.2N (0.2N) alloys against the cooling rate after $\beta$ solution treatment and the microstructure changes during slow cooling and aging have been investigated.

(1) In the $\mathrm{N}$-free alloy, superelasticity appears when the cooling rate is between $50 \mathrm{~K} / \mathrm{s}$ and $22 \mathrm{~K} / \mathrm{s}$. The rate of $22 \mathrm{~K} / \mathrm{s}$ is the most favorable for improving superelasticity. In the $0.2 \mathrm{~N}$ alloy, superelasticity appears in all conditions except for $2 \mathrm{~K} / \mathrm{s}$. Cooling at $50 \mathrm{~K} / \mathrm{s}$ is the most favorable for improving superelasticity and the maximum recovered strain of $3.2 \%$ can be obtained.

(2) Microstructural change improving superelasticity during continuous cooling is precipitation of isothermal- $\omega$ phase or its precursor phenomenon.

\section{Acknowledgement}

The authors are grateful to Kobe Steel, Ltd. for providing the materials used in this study.

\section{REFERENCES}

1) C. Baker: Met. Sci. J. 5 (1971) 92-100.

2) H. Sasano and T. Suzuki: Proc. 5th Int. Conf. on Titanium, (1985) pp. 1667-1674.

3) J. S. Lee Park, C. Y. Lei and C. M. Wayman: Mater. Sci. Eng. A 132 (1991) 237-244

4) T. W. Duerig, J. Albrecht, D. Richter and P. Fischer: Acta Metall. 30 (1982) 2161-2172.

5) E. Takahashi, T. Sakurai, S. Watanabe, N. Masahashi and S. Hanada: Mater. Trans. 43 (2002) 2978-2983.

6) H. Y. Kim, Y. Ikeda, J. I. Kim, H. Hosoda and S. Miyazaki: Acta Mater. 54 (2006) 2419-2429.

7) Y. Fukui, T. Inamura, H. Hosoda, K. Wakashima and S. Miyazaki: Mater. Trans. 45 (2004) 1077-1082.

8) J. I. Kim, H. Y. Kim, H. Hosoda and S. Miyazaki: Mater. Trans. 46 (2005) 852-857.

9) J. I. Kim, H. Y. Kim, T. Inamura, H. Hosoda and S. Miyazaki: Mater. Trans. 47 (2006) 505-512.

10) H. Y. Kim, Y. Ohmatsu, J. I. Kim, H. Hosoda and S. Miyazaki: Mater. Trans. 45 (2004) 1090-1095.

11) T. Maeshima and M. Nishida: Mater. Trans. 45 (2004) 1096-1100.

12) T. Maeshima and M. Nishida: Mater. Trans. 45 (2004) 1101-1105.

13) T. Maeshima, S. Ushimaru, K. Yamauchi and M. Nishida: Mater. Trans. 47 (2006) 513-517.

14) H. Y. Kim, J. I. Kim, T. Inamura, H. Hosoda and S. Miyazaki: Mater. Sci. Eng. A 438-440 (2006) 839-843.

15) H. Hosoda, Y. Kinoshita, Y. Fukui, T. Inamura, K. Wakashima, H. Y. Kim and S. Miyazaki: Mater. Sci. Eng. A 438-440 (2006) 870-874.

16) T. Furuhara, S. Annaka and T. Maki: J. Mater. Eng. Perform. 14 (2005) 761-764.

17) T. Furuhara, S. Annaka, Y. Tomio and T. Maki: Mater. Sci. Eng. A 438-440 (2006) 825-829.

18) Y. Tomio, T. Furuhara and T. Maki: Proc. 11th Int. Conf. on Titanium, (2007) pp. 571-574.

19) T. W. Duerig, G. T. Terlinde and J. C. Williams: Metall. Trans. A 11A (1980) 1987-1998.

20) G. H. Narayanan, T. S. Luhman, T. F. Archbold, R. Taggart and D. H. Polonis: Metallography 4 (1971) 343-358.

21) S. Komatsu, M. Ikeda, T. Sugimoto, K. Kamei, O. Maesaki and M. Kojima: Mater. Sci. Eng. A 213 (1996) 61-65.

22) Y. Ohmori, H. Natui, K. Nakai and H. Ohtsubo: Mater. Trans. JIM 39 (1998) 40-48.

23) M. Ikeda, S. Komatsu, T. Sugimoto and K. Kamei: J. Japan Inst. Metals 53 (1989) 664-671. 